\title{
EDITORIAL
}

\section{Does Fellow Participation Increase the Adenoma Detection Rate?}

\author{
Emanuele Sinagra $^{1} \cdot$ Rita Alloro $^{2} \cdot$ Ilaria Tarantino $^{3}$ \\ Accepted: 31 January 2021 / Published online: 21 February 2021 \\ (C) The Author(s), under exclusive licence to Springer Science+Business Media, LLC part of Springer Nature 2021
}

The primary operator-dependent quality indicator for colonoscopy is the adenoma detection rate (ADR), defined as the proportion of screening colonoscopies detecting at least one adenoma, which ideally should be $\geq 25 \%$ overall $(\geq 30$ for male patients and $\geq 20 \%$ for female patients) [1]. In fact, the ADR is inversely related to both the risk of interval colorectal cancer (cancer diagnosed on a surveillance exam after an initial negative screening colonoscopy), as well as death caused by interval colorectal cancer [2, 3]. Several factors affect the ADR, including: (1) patient features such as age, gender, and family history; (2) procedural characteristics such as optimized colon cleansing, withdrawal time, and methods of sedation; (3) ancillary maneuvers such as positioning, right colon retroflexion, and the use of wateraided methods; (4) technologic advances such as new generation endoscopes, increased field of view, add-on tools, virtual chromoendoscopy, and artificial intelligence; and (5) endoscopist experience $[4,5]$.

Interestingly, in this issue of Digestive Diseases and Sciences, Araujo et al. [6], in their retrospective multicenter observational study, aim to determine the impact of gastroenterology fellow participation on the ADR. They demonstrated that fellow participation improved the overall ADR, right-sided ADR (detection rate for polyps in the right colon), and advanced ADR (detection rate for advanced polyps), though with institution-specific results. Furthermore, they showed that right-sided ADR was improved according

Emanuele Sinagra

emanuelesinagra83@googlemail.com

1 Gastroenterology and Endoscopy Unit, Fondazione Istituto G. Giglio, Contrada Pietrapollastra Pisciotto, 90015 Cefalù, Palermo, Italy

2 Department of Surgical, Oncological and Oral Sciences (Di.Chir.On.S.), Unit of General and Oncological Surgery, Paolo Giaccone University Hospital, University of Palermo, Via del Vespro 129, 90127 Palermo, Italy

3 Endoscopy Service, Department of Diagnostic and Therapeutic Services, Istituto Mediterraneo Per I Trapianti E Terapie Ad Alta Specializzazione, Palermo, Italy to fellowship seniority (even though seniority did not affect overall ADR and advanced ADR), whereas fellow sex did not affect the ADR.

The main strengths of this study are the inclusion of a large population sample and the analysis of the impact of fellow participation on ADR in an average-risk screening population. Furthermore, since ADR is an operator-dependent indicator, the retrospective design of this study minimizes observer bias as it relates to endoscopist performance.

To date, the contribution of fellow participation to the ADR remains debatable. In fact, literature data are conflicting, since prior studies have also shown no [7] or even negative [8] impact of fellow involvement on ADR associated with fellow participation. A probable explanation of this difference was suggested by geographic differences in adenoma prevalence, the demographic differences of the institution in which the studies were performed, and the global variations in ADRs among fellows and attending physicians [6].

When considering the weaknesses of the present study, the authors mention the lack of data regarding the proportion of time that a fellow spent performing the procedure versus observing the attending, and the absence of the reporting of withdrawal times and overall procedure time. [6].

In order to better understand these elements, a comprehensive knowledge of the factors that affect ADR participation is needed (Fig. 1). For example, the application of the aforementioned technical measures [4] should be standardized during the fellow training and registered in order to define which factors could be responsible for superior performance of obtaining an increased ADR when a fellow is involved. Furthermore, the advantages of advanced technology in this setting should be emphasized.

As the rate of new medical knowledge rises, technologic tools such as virtual chromoendoscopy, artificial intelligence, and add-on tools such as caps, rings, and balloons are needed in order to enable healthcare professionals to effectively use this knowledge to practice medicine [9]. Therefore, younger doctors need to be adequately introduced to these new technologies during their training, with the hope of reducing costs and improving the quality 
Fig. 1 Old and emerging factors affecting the adenoma detection rate

\section{Factors affecting Adenoma Detection Rate}

\section{Fellow participation}

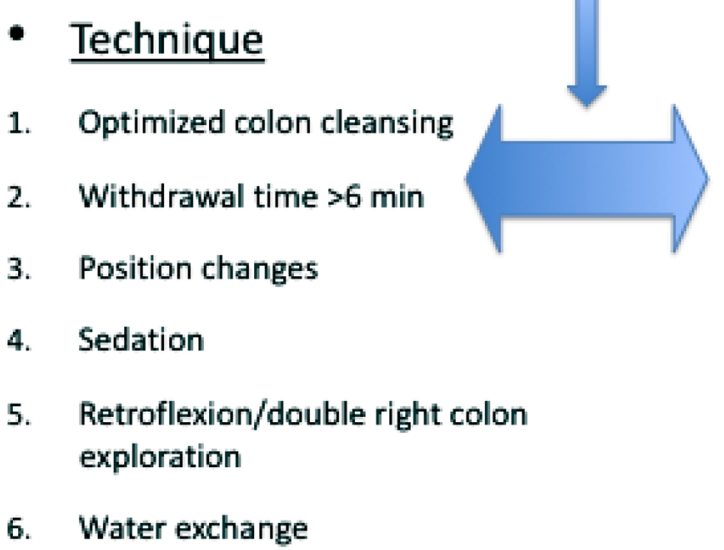

- Technology

1. New-generation endoscopes (e.g. HD)

2. Increased field of view

3. Add-on tools (e.g. caps, rings, balloons etc.)

4. Virtual chromoendoscopy

5. Artificial Intelligence of and access to health care. The success of technology and its place in medicine and health care highly depend on whether it can be supported by evidence-based guidelines and if the reluctance of medical professionals to use it can be overcome [9].

Finally, the impact of fellow participation on the sessile serrated ADR should be investigated. In fact, sessile serrated adenomata are difficult to detect due to their subtle morphology, and even when detected, are often incompletely resected. Furthermore, some sessile serrated adenomas are reported to progress to invasive cancer in a short time period [10].

In conclusion, the effect of fellow participation is a factor that should be considered as a further tool to increase ADR (Fig. 1) among these already known. In fact, this beneficial impact could be due to the observation that even an experienced endoscopist might not perceive the presence of a small polyp due to "inattentional blindness" (failure to visualize something if attention is focused elsewhere) or "change blindness" (due to physiologic eye movements). With the help of the fellows, some of these deficiencies may be attenuated, thus improving ADR, even in the case of diminutive $(<5 \mathrm{~mm})$ lesions, that are at higher risk of being missed. Further research is needed in order to assess the factors related to the real effectiveness of fellow participation in improving ADR, and in order to standardize these factors during fellow training.

\section{Compliance with Ethical Standards}

Conflict of interest The authors declare no conflict of interest.

\section{References}

1. Maida M, Macaluso FS, Ianiro G et al. Screening of colorectal cancer: Present and future. Expert Rev Anticancer Ther. 2017;17:11311146. https://doi.org/10.1080/14737140.2017.1392243.

2. Corley DA, Jensen CD, Marks AR et al. Adenoma detection rate and risk of colorectal cancer and death. $N$ Engl J Med 2014;370:1298-1306

3. Kaminski MF, Regula J, Kraszewska E et al. Quality indicators for colonoscopy and the risk of interval cancer. $N$ Engl J Med 2010;362:1795-1803

4. Maida M, Morreale G, Sinagra E et al. Quality measures improving endoscopic screening of colorectal cancer: a review of the literature. Expert Rev Anticancer Ther. 2019;19:223-235. https://doi. org/10.1080/14737140.2019.1565999.

5. Sinagra E, Badalamenti M, Maida $M$ et al. Use of artificial intelligence in improving adenoma detection rate during colonoscopy: Might both endoscopists and pathologists be further helped. World J Gastroenterol. 2020;26:5911-5918. https://doi.org/10.3748/wjg. v26.i39.5911.

6. Araujo J, Jaiswal P, Ragunathan K et al. Impact of fellow participation during colonoscopy on adenoma detection rates. Dig Dis Sci. (Epub ahead of print). https://doi.org/10.1007/s10620-021-06887-6.

7. Friedman M, Arora G, Green J. Fellow involvement during colonoscopy does not reduce adenoma detection rate. Dig Dis Sci 2011;56:919

8. Kim YD, Bae WK, Choi YH et al. Difference in adenoma detection rates according to colonoscopic withdrawal times and the level of expertise. Korean J Gastroenterol 2014;64:278-283

9. Sinagra E, Rossi F, Raimondo D. Use of artificial intelligence in endoscopic training: Is deskilling a real fear? Gastroenterology. 2021. https://doi.org/10.1053/j.gastro.2020.12.065.

10. Ohki D, Tsuji Y, Shinozaki T et al. Sessile serrated adenoma detection rate is correlated with adenoma detection rate. World J Gastrointest Oncol. 2018;10:82-90. https://doi.org/10.4251/wjgo.v10. i3.82.

Publisher's Note Springer Nature remains neutral with regard to jurisdictional claims in published maps and institutional affiliations. 